\title{
Perceptions of Primary Care Notes by Patients With Mental Health Diagnoses
}

Jared W. Klein $M D, M P H^{1}$

Sue Peacock, MS ${ }^{1}$

Judith I. Tsui, MD, MPH

Stephen F. O'Neill, BCD, JD2

Catberine M. DesRocbes, $P b D^{2}$

Joann G. Elmore, MD, MPH

'Department of Medicine, University of Washington School of Medicine, Seattle, Washington

${ }^{2}$ Beth Israel Deaconess Medical Center, Harvard Medical School, Boston, Massachusetts

${ }^{3}$ David Geffen School of Medicine at University of California Los Angeles, Los Angeles, California

Conflicts of interest: authors report none.

\section{CORRESPONDING AUTHOR}

Joann G. Elmore, MD, MPH

David Geffen School of Medicine at

University of California Los Angeles

Department of Medicine

National Clinician Scholars Program

10940 Wilshire Blvd, Suite 700

Los Angeles, CA 90024

jelmore@mednet.ucla.edu

\begin{abstract}
There are concerns regarding whether patients with mental illness should be provided with access to their electronic medical records. This study compared perceptions of patients with $(n=400)$ and without $(n=2,134)$ a mental health diagnosis regarding access to primary care clinic notes through secure online portals. Eligible participants viewed at least 1 clinic note during a 12-month period. Administrative data were used to stratify patients by mental health diagnosis. As we hypothesized, patients with and without mental health diagnoses had similar perceptions about online access to notes.
\end{abstract}

Ann Fam Med 2018;16:343-345. https://doi.org/10.1370/afm.2287.

\section{INTRODUCTION}

Primary care providers deliver a substantial proportion of mental health care in the United States. ${ }^{1,2}$ Over the past decade, increasing numbers of primary care practices have been making electronic medical records, including clinical notes, available to patients via secure patient portals. A growing body of evidence suggests this access could help patients be more engaged in their health care. ${ }^{3,4}$ Despite the purported benefits, mental health clinicians ${ }^{5}$ and others have lingering concerns about sharing clinic notes with certain patients, specifically those with psychiatric comorbidities. We hypothesize that patients with mental health diagnoses will have similar opinions about the potential impact of reading primary care clinic notes online compared with patients without mental illness.

\section{METHODS}

In this study we analyzed data from the original OpenNotes study, which provided patients with access to their full electronic medical record, including doctors' clinic notes, at 3 health care systems. ${ }^{6}$ Following implementation of OpenNotes, patients completed a survey regarding their perceptions of reading doctors' notes online. ${ }^{6}$ Survey questions were developed from prior qualitative analyses. ${ }^{3,6}$ For simplification of analysis and presentation of results, 4-point Likert scale responses were dichotomized as either agree/ somewhat agree or disagree/somewhat disagree.

Our analysis was restricted to patients at a single site where clinical diagnosis data were available. Eligible subjects were adult primary care patients with at least 1 clinic visit during the intervention period who reported reading at least 1 clinic note online. Mental health diagnoses were determined based on documented International Classification of Diseases, Ninth Revision (ICD-9) codes (Supplemental Appendix 1, http://www. annfammed.org/content/16/4/343/suppl/DC1). We compared the perceptions of patients with and without mental health diagnoses following the implementation of OpenNotes.

Comparisons were initially made using the $\chi^{2}$ statistic for categorical dependent variables, then multivariate regression was performed to control for possible confounders. All statistical analyses were conducted 
using SAS software, version 9.4 (SAS Institute Inc). The institutional review boards of the University of Washington and Beth Israel Deaconess Medical Center approved the study procedures.

\section{RESULTS}

The survey was completed by 2,534 patients who reported reading at least 1 of their clinic notes $(n=400$ with mental health diagnoses and $n=2,134$ without), representing a response rate of $37 \%$. Patient characteristics are shown in Table 1. Most patients had positive perceptions about OpenNotes (Table 2). Patients with mental health diagnoses were significantly more likely to report worry compared with other patients $(8.2 \%$ vs $5.3 \% ; P<.029)$, however, after adjustment for variables independently associated with mental health diagnoses (sex, race, education, and employment) there were no differences in perceptions about access to online notes between patients with or without mental health diagnoses (data not shown).

\section{DISCUSSION}

Compared with patients without mental health diagnoses, primary care patients with mental health diagnoses were similarly enthusiastic about the utility of reading their doctors' notes online. Giving patients with mental illness access to their clinic notes may help them engage more actively in their treatment. ${ }^{7}$ Additionally, opportunities for improved communication between patient and care provider may enhance trust, ${ }^{8}$ which is particularly important given the stigma surrounding mental illness. Providing patient access to notes could also stimulate clinicians to craft notes that are nonjudgmental, another step in strengthening the patient-doctor relationship. ${ }^{9}$

As with any intervention, the risks of access to certain clinical information in doctors' notes could at times outweigh the potential benefit. While we noted that patients with mental illness were more likely to worry than patients without mental illness, this association was not significant after adjusting for possible confounders. Ensuring that note contents correspond with visit conversations might reassure apprehensive patients and could even engender greater patient-doctor trust..$^{10}$ Patients at imminent risk of self- harm, with profoundly decompensated mental illness, or suffering from intimate partner violence might need to have particular notes blocked from the online portal for safety reasons. Most health systems have protocols for blocking part or all of clinic notes from the patient portal, although HIPAA protects patients' right to view their medical records with few restrictions. ${ }^{7}$

A primary limitation of this study is that the original OpenNotes study was not specifically designed to investigate the perceptions of patients with mental health disorders. Administrative data was used to identify patients with mental health problems and a broad array of mental health diagnoses was included. There was likely extensive variability in how mental health diagnoses were addressed in clinic notes. Mental illness can be under-recognized and less severe in the primary care setting compared with behavioral health prac-
Table 1. Patient Characteristics

\begin{tabular}{|c|c|c|c|}
\hline Characteristic $^{a}$ & $\begin{array}{l}\text { Mental Health } \\
\text { Diagnosis } \\
\text { (n= 400) } \\
\text { No. }(\%)\end{array}$ & $\begin{array}{c}\text { No Mental } \\
\text { Health Diagnosis } \\
(n=2,134) \\
\text { No. }(\%)\end{array}$ & $\begin{array}{c}P \\
\text { Value }\end{array}$ \\
\hline Age & & & .48 \\
\hline$<50 y$ & $133(33)$ & $671(31)$ & \\
\hline$\geq 50 y$ & $267(67)$ & $1,462(69)$ & \\
\hline Sex & & & .011 \\
\hline Male & $91(31)$ & $641(39)$ & \\
\hline Female & $203(69)$ & $1014(61)$ & \\
\hline Education & & & $<.001$ \\
\hline High school/GED or less & $30(8)$ & $109(5)$ & \\
\hline Some college & $106(27)$ & $370(18)$ & \\
\hline College graduate & $90(23)$ & $473(23)$ & \\
\hline Post college & $162(42)$ & $1,147(55)$ & \\
\hline Employment & & & $<.001$ \\
\hline Not employed & $46(12)$ & $106(5)$ & \\
\hline Retired & $69(19)$ & $317(16)$ & \\
\hline $\begin{array}{l}\text { Employed/self-employed/ } \\
\text { homemaker }\end{array}$ & 257 (69) & $1,608(79)$ & \\
\hline Race & & & .005 \\
\hline Black & $23(6)$ & $59(3)$ & \\
\hline Multi-racial/other & $25(7)$ & $167(8)$ & \\
\hline White & $335(87)$ & $1,829(89)$ & \\
\hline \multicolumn{4}{|l|}{$\begin{array}{l}\text { Specific mental health } \\
\text { diagnosis }^{d}\end{array}$} \\
\hline Depression & $259(65)$ & & \\
\hline Anxiety disorder & $180(45)$ & & \\
\hline Stress disorders & $47(12)$ & & \\
\hline Bipolar disorder & $23(6)$ & & \\
\hline Psychotic disorder & $7(2)$ & & \\
\hline \multicolumn{4}{|l|}{$\mathrm{GED}=$ general equivalency diploma. } \\
\hline \multicolumn{4}{|c|}{$\begin{array}{l}\text { a Missing data occur in all patient characteristics. } \\
\text { b Mental health diagnosis is determined by International Classification of Diseases, Ninth Revision } \\
\text { (ICD-9) codes. All diagnoses identified before the survey. } \\
\text { c } P \text { value for } \chi^{2} \text { statistic. } \\
{ }^{d} \text { Diagnoses are not mutually exclusive. }\end{array}$} \\
\hline
\end{tabular}


Table 2: Comparison of Patients With and Without a Mental Health Diagnosis Who Agree/Somewhat Agree With Perception Statements Regarding OpenNotes

\begin{tabular}{lcc}
\hline Perception & $\begin{array}{c}\text { Mental Health } \\
\text { Diagnosis }(\mathbf{n}=\mathbf{4 0 0}) \\
\text { No. (\%) }\end{array}$ & $\begin{array}{c}\text { No Mental Health } \\
\text { Diagnosis }(\mathbf{n}=\mathbf{2 , 1 3 4 )} \\
\text { No. (\%) }\end{array}$ \\
\hline Positive & & $1,017(67.6)$ \\
I do better with taking my medications as prescribed & $236(74.0)$ & $1,471(81.0)$ \\
I take better care of myself & $296(83.6)$ & $1,789(91.3)$ \\
I feel more in control of my health care & $336(92.3)$ & $1,777(91.7)$ \\
I understand my health and medical conditions better & $341(92.9)$ & $1,549(85.0)$ \\
I am better prepared for visits & $298(87.6)$ & $1,763(91.6)$ \\
I remember the plan for my care better & $346(94.8)$ & $104(5.3)$ \\
Negative & $30(8.2)$ & $49(2.5)$ \\
I worry more & $5(1.4)$ & $746(38.5)$ \\
The notes are more confusing than helpful & $152(41.2)$ & .025 \\
I am concerned about my privacy & & .44 \\
\hline Note: Mental health diagnosis determined by International Classification of Diseases, Ninth Revision (ICD-9) codes from clinic visits during period of note availability. All \\
diagnoses identified before the post survey.
\end{tabular}

tices. ${ }^{11}$ It is not known if patients' perceptions would be different if they read psychiatrists' or behavioral health providers' detailed notes rather than primary care providers' notes. Small numbers in some of the perception categories limit the interpretation of our multivariate analyses. Finally, perceptions were self-reported and gathered from early experiences of patients using secure web portals to access their medical records.

In conclusion, we found that patients with mental health diagnoses had similar perceptions about reading their primary care clinic notes as other patients. Providing online access to all patients, including those with mental illness, might contribute to greater adherence to treatment plans and patient-doctor trust, and potentially help to destigmatize mental illness. However, we need to more fully understand the spectrum of benefits and risks of clinic note access in patients with mental health problems and identify interventions to mitigate potential adverse effects of this new tool.

To read or post commentaries in response to this article, see it online at http://www.AnnFamMed.org/content/16/4/343.

Submitted August 8, 2017; submitted, revised, January 5, 2018; accepted February 14, 2018.

Key words: electronic health records; mental health; patient paticipation; patient portals

Funding support: The authors gratefully acknowledge support from The Commonwealth Fund, Robert Wood Johnson Foundation, Gordon and Betty Moore Foundation, Peterson Center on Healthcare, and Cambia Health Foundation.

Supplementary Materials: Available at http://www.AnnFamMed. org/content/16/4/343/suppl/DC1/.

\section{References}

1. Regier DA, Narrow WE, Rae DS, Manderscheid RW, Locke BZ, Goodwin FK. The de facto US mental and addictive disorders service system. Epidemiologic catchment area prospective 1-year prevalence rates of disorders and services. Arch Gen Psychiatry. 1993;50(2):85-94.

2. Abed Faghri NM, Boisvert CM, Faghri S. Understanding the expanding role of primary care physicians (PCPS) to primary psychiatric care physicians (PPCPs): enhancing the assessment and treatment of psychiatric conditions. Ment Health Fam Med. 2010;7(1):17-25.

3. Delbanco T, Walker J, Bell SK, et al. Inviting patients to read their doctors' notes: a quasi-experimental study and a look ahead. Ann Intern Med. 2012;157(7):461-470.

4. Wolff JL, Darer JD, Berger A, et al. Inviting patients and care partners to read doctors' notes: OpenNotes and shared access to electronic medical records. J Am Med Inform Assoc. 2017;24(e1) e166-e172.

5. Dobscha SK, Denneson LM, Jacobson LE, Williams HB, Cromer $\mathrm{R}$, Woods S. VA mental health clinician experiences and attitudes toward OpenNotes. Gen Hosp Psychiatry. 2016;38:89-93.

6. Leveille SG, Walker J, Ralston JD, Ross SE, Elmore JG, Delbanco T. Evaluating the impact of patients' online access to doctors' visit notes: designing and executing the OpenNotes project. BMC Med Inform Decis Mak. 2012;12:32.

7. Kahn MW, Bell SK, Walker J, Delbanco T. A piece of my mind. Let's show patients their mental health records. JAMA. 2014;311(13): 1291-1292.

8. Bell SK, Mejilla R, Anselmo M, et al. When doctors share visit notes with patients: a study of patient and doctor perceptions of documentation errors, safety opportunities and the patient-doctor relationship. BMJ Qual Saf. 2017;26(4):262-270.

9. Klein JW, Jackson SL, Bell SK, et al. Your patient is now reading your note: opportunities, problems, and prospects. Am J Med. 2016; 129(10):1018-1021.

10. Cromer R, Denneson LM, Pisciotta M, Williams H, Woods S, Dobscha SK. Trust in mental health clinicians among patients who access clinical notes online. Psychiatr Serv. 2017;68(5):520-523.

11. Vermani M, Marcus M, Katzman MA. Rates of detection of mood and anxiety disorders in primary care: a descriptive, cross-sectional study. Prim Care Companion CNS Disord. 2011;13(2):13. 